\title{
Foreword: plant and canopy architecture impact on disease epidemiology and pest development
}

\author{
Bernard Tivoli • Didier Andrivon • \\ Alain Baranger • Agnès Calonnec • Michael Jeger
}

Accepted: 3 October 2012 / Published online: 11 October 2012

(C) The Author(s) 2012. This article is published with open access at Springerlink.com

Keywords Architectural features · Epidemiological processes - Innovative crop protection system .

Interdisciplinary research

Developing and implementing alternatives to the 'pesticide only' approach requires improvements in current pest control methods (using Decision Support Systems, longer rotations, more robust cultivars, mixed crops, crop management...), but also the generation of new knowledge that can be put to use in integrated and innovative crop production systems. Innovative studies are now needed that place the plant at the centre of the crop protection system; and, to do so, analyse how plant architectural traits can be used to limit or suppress disease epidemics.

B. Tivoli $(\bowtie) \cdot$ D. Andrivon $\cdot$ A. Baranger

INRA, UMR1349 IGEPP,

35653 Le Rheu, France

e-mail: bernard.tivoli@rennes.inra.fr

A. Calonnec

INRA, UMR 1065 SAVE, Université de Bordeaux, 33883 Villenave d'Ornon, France

\section{Jeger}

Division of Ecology and Evolution and Centre for Environmental Policy, Imperial College London,

Silwood Park campus,

Ascot SL5 7PY, UK
This topic is not new: it was indeed an important field of research before the advent of the 'pesticide only' approach that has dominated the practise of plant protection since the 1970s. Today there is a renewed impetus, firstly because of the societal pressure to develop environmentally friendlier pest control strategies, but also thanks to the advances in experimental and modelling activities which now allow truly interdisciplinary work when tackling complex systems. This volume puts together the main keynote papers delivered to the conference "Plant and Canopy Architecture Impact on Disease Epidemiology and Pest Development", held in Rennes, France, in July 2012. The papers illustrate disciplinary complementarities, by including contributions from plant pathologists, disease epidemiologists, entomologists, agronomists, plant and crop physiologists, bioclimatologists, plant geneticists and applied mathematicians. Many papers are co-authored by specialists from different disciplinary origins, highlighting the integrative efforts that need to be made to tackle a problem that may appear at first to be relevant only to plant pathologists.

Why is such an interdisciplinary research strategy actually required? Simply, because the question at

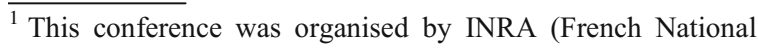
Institute of Agronomical Research), Agrocampus Ouest Institute and SFP (French Plant Pathology Society), with funding from the French National Research Agency ANR (ARCHIDEMIO project grant ANR-08-STRA-04), INRA, the Brittany Region and Rennes Métropole.
} 
hand is not, as might be thought initially, restricted to an epidemiology problem (identifying the processes that are modified by changes in the structure of crop plants and during crop growth with consequences in pest dynamics), but rather targets the management of an infected crop - i.e. of two interacting and interdependent populations under human actions. The contributions to this volume therefore meet different objectives:

- to define plant and canopy architecture in the context of plant disease epidemiology (Costes et al., this issue), and analyse the main characteristics that have to be known for epidemics and pathogen development (Tivoli et al., this issue);

- to dissect and disentangle the direct impact of some architectural characteristics on pathogen processes and epidemic behaviour (Calonnec et al., this issue; Scherm et al., this issue) and their consequences on pathogen dynamics through indirect changes in the canopy microclimate (Richard et al., this issue);

- to understand and use the genetic control of architectural traits involved in epidemic reduction (Miklas et al., this issue);
- to quantify the impact of these modifications on yield losses (Grumet and Ando, this issue; Smith et al., this issue);

- to investigate for various crops the possibilities for combining architectural management and other disease control methods, through the use of cultural practices or genetic resistance, to reduce the use of pesticides (Mc Donald et al., this issue).

Finally, despite concerted research efforts, much remains to be done before we can take full advantage of the possibilities offered by the manipulations of the architecture of individual plants or of whole plant canopies to keep pathogens under control. This volume therefore also includes two 'opinion' papers, aiming at providing clues as to how scientists could deal with these issues in the context of a changing climate (Chakraborty and Pangga, this issue), or when the timelines of breeding operations and adoption of new plant material remain long (Andrivon et al, this issue). We sincerely hope that the contributions to this volume will provide incentives for further collaborative work and for future research directions.

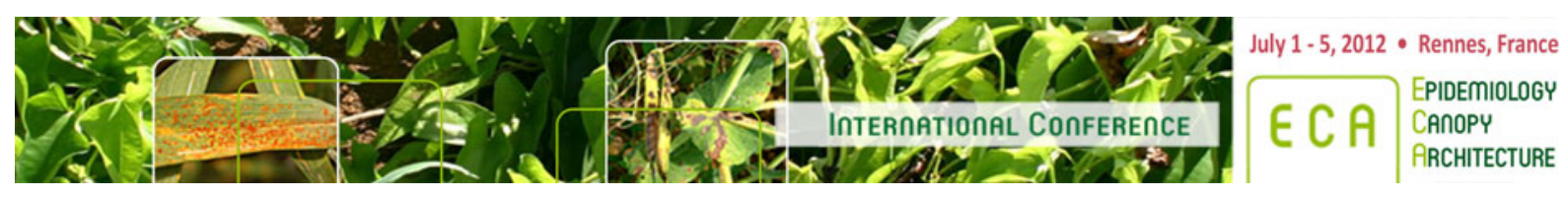

Open Access This article is distributed under the terms of the Creative Commons Attribution License which permits any use, distribution, and reproduction in any medium, provided the original author(s) and the source are credited. 